\title{
Gamma-phase influence on shape memory properties in Ni-Mn- Co-Ga-Gd high-temperature shape memory alloys
}

\author{
Wei Zhang ${ }^{1} \cdot$ Xin Zhang $^{1} \cdot$ Qian Wang $^{1} \cdot$ Qing-Suo Liu ${ }^{1}$
}

Received: 13 September 2017/Revised: 4 October 2017/Published online: 4 November 2017

(C) The Chinese Society for Metals and Springer-Verlag GmbH Germany 2017

\begin{abstract}
The effect of $\gamma$-phase on two-way shape memory effect (TWSME) of polycrystalline $\mathrm{Ni}_{56} \mathrm{Mn}_{25-x} \mathrm{Co}_{x} \mathrm{Ga}_{18.9} \mathrm{Gd}_{0.1}$ alloys was investigated. The results show that an appropriate amount of ductile $\gamma$-phase significantly enhances the TWSME. The largest TWSME of $1.4 \%$ without training is observed in $\mathrm{Ni}_{56} \mathrm{Mn}_{21} \mathrm{Co}_{4} \mathrm{Ga}_{18.9} \mathrm{Gd}_{0.1}$ alloy, and this value is increased to $2.0 \%$ after thermomechanical training. The as-trained TWSME decays over the first five thermal cycles and then reaches a stable value as the number of cycles further increasing. Only the degradation of $0.2 \%$ is observed after 100 thermal cycles. The better TWSME and thermal stability are ascribed to the stable extra stress field formed by the plastically deformed $\gamma$-phase.
\end{abstract}

KEY WORDS: Shape memory alloys; Ni-Mn-Ga alloys; Thermomechanical training; Second phase; Twoway shape memory effect

\section{Introduction}

Shape memory alloys (SMAs) have been successfully used in a variety of technical areas for their unique abilities such as damping characteristics, shape memory effect (SME), pseudo elasticity, etc. In various properties of SMAs, twoway shape memory effect (TWSME) is the most suitable one to be applied in actuators. TWSME means the SMAs are able to "remember" a geometrical shape at high temperature (above $A_{f}$ ) and another shape at low temperature (below $M_{f}$ ), and during the repeated heating and

Available online at http://link.springer.com/journal/40195.

Xin Zhang

zhangxin3510110@126.com

$\triangle$ Qing-Suo Liu

qingsuoliu@eyou.com

1 School of Materials Science and Engineering, Tianjin University of Technology, Tianjin 300384, China cooling, the SMAs change their shape between these two shapes without resetting force. To date, Ti-Ni alloy is widely researched in SMAs actuators, and the outstanding TWSME makes it exhibit excellent performance in practical application [1, 2]. However, the transformation temperature of $\mathrm{Ti}-\mathrm{Ni}$ alloy is less than $100{ }^{\circ} \mathrm{C}$, leading to the $\mathrm{Ti}-\mathrm{Ni}$ actuators cannot be used in high-temperature environment. Therefore, the development of high-temperature shape memory alloys (HTSMAs) will become a research focus in the actuator field.

Currently, Ni-Mn-Ga alloys have attracted more and more interests for their high-transformation temperature, large SME and high stability [3-9]. The prominent performance in the high-temperature environment makes $\mathrm{Ni}-$ $\mathrm{Mn}-\mathrm{Ga}$ alloy possible to become an excellent candidate for high-temperature actuators. Meanwhile, the TWSME has also been observed in Ni-Mn-Ga thin films and bulk single crystals [10-14]. In practical applications, polycrystalline alloys have an advantage over thin film and single crystals because of their easy preparation. However, there is few 
reported study of TWSME for polycrystalline $\mathrm{Ni}-\mathrm{Mn}-\mathrm{Ga}$ HTSMA. It is well known that the second phase in some polycrystalline SMAs like Ti-Ni [15] and $\mathrm{Cu}-\mathrm{Zn}-\mathrm{Al}$ [16] can obviously affect their TWSME. Thus, to study the effect of second phase on TWSME of Ni-Mn-Ga alloys is necessary.

The second phase with different characteristics can be introduced in Ni-Mn-Ga alloys by different forth-element addition. For example, both the additions of elements of $\mathrm{B}$ and $\mathrm{Gd}$ can introduce hard-brittle second phase [6,9]. In contrast, the elements such as $\mathrm{Co}, \mathrm{Cu}$ and $\mathrm{Cr}$ lead to the formation of ductile $\gamma$-phase $[8,17,18]$. Our previous study proved that the hard-brittle second phase can improve TWSME of polycrystalline Ni-Mn-Ga HTSMAs, and the TWSME of $3.5 \%$ was observed, and this TWSME remained at $2.5 \%$ after 50 thermal cycles [19]. Nevertheless, the influence of ductile $\gamma$-phase on TWSME of polycrystalline Ni-Mn-Ga HTSMAs has not yet been studied. In this paper, the soft gamma-phase is formed through the Co element doping, and the TWSME of polycrystalline $\mathrm{Ni}_{56} \mathrm{Mn}_{25-x} \mathrm{Co}_{x} \mathrm{Ga}_{18.9} \mathrm{Gd}_{0.1}$ HTSMAs is investigated.

\section{Materials and Methods}

The nominal compositions of the alloys studied were $\mathrm{Ni}_{56} \mathrm{Mn}_{25-x} \mathrm{Co}_{x} \mathrm{Ga}_{18.9} \mathrm{Gd}_{0.1}(x=1,2,4$ and 8$)$. High-purity nickel, manganese, cobalt, gallium and gadolinium, with a purity level of 99.99, 99.7, 99.99, 99.99 and 99.99\%, were melted in a non-consumed vacuum arc furnace under argon atmosphere for preparing alloys. The ingots were remelted eight times to ensure homogeneity. The samples were annealed in vacuum quartz tubes at $800{ }^{\circ} \mathrm{C}$ for $24 \mathrm{~h}$ then quenched into ice water.

XRD measurements were performed by Rigaku D/max$\mathrm{rB}$ with $\mathrm{Cu} K_{\alpha}$ radiation. The microstructures were surveyed by MX2600FE scanning electron microscopy (SEM). The martensitic transformation temperatures were determined by differential scanning calorimetry (DSC) with heating and cooling rate of $20^{\circ} \mathrm{C} / \mathrm{min}$. The SME and TWSME were studied by compressive tests in the universal mechanical testing machine. The samples' dimension and deformation rate were $\Phi 3 \mathrm{~mm} \times 5 \mathrm{~mm}$ and $0.2 \mathrm{~mm} / \mathrm{min}$, respectively. The heights of the samples were measured before loading $\left(L_{0}\right)$, after loading $\left(L_{1}\right)$, after unloading $\left(L_{2}\right)$, after heating $\left(L_{3}\right)$ and after cooling to room temperature $\left(L_{4}\right)$ by a micrometer with an accuracy of $0.01 \mathrm{~mm}$. The pre-strain during compression was defined as $\varepsilon_{\text {pre }}=$ $\left(L_{0}-L_{1}\right) / L_{0} \times 100 \%$. The SME and TWSME were obtained as: $\left(L_{3}-L_{2}\right) / L_{0} \times 100 \%$ and $\left(L_{3}-L_{4}\right) / L_{0} \times 100 \%$, respectively. Two-way shape memory training [20] experiment was conducted by thermomechanical cycles. A constant compressive strain was applied to the samples at room temperature (martensitic state). After deformation, the compressive samples were heated to the temperature above $A_{f}$ (training temperature) for complete shape recovery and then cooled to room temperature. At each test, the above steps were repeated for 10 times.

\section{Results and Discussion}

Figure 1 shows the secondary electron images of the $\mathrm{Ni}_{56} \mathrm{Mn}_{25-x} \mathrm{Co}_{x} \mathrm{Ga}_{18.9} \mathrm{Gd}_{0.1} \quad(x=1,2,4$ and 8$)$ alloys observed by SEM. Figure $1 \mathrm{a}$ shows that the $\mathrm{Ni}_{56} \mathrm{Mn}_{24}$ $\mathrm{Co}_{1} \mathrm{Ga}_{18.9} \mathrm{Gd}_{0.1}$ alloy exhibits single-phase features of the martensite characterized by typical lamellar twin structures. When the Co content is at $2 \%$, the second phase with granular shape uniformly disperses among the martensitic variants (Fig. 1b). The size and volume ratio of the second phase increases with the Co content increasing as shown in Fig. 1c and d, and some parts of the second phase join together to form slender bars and irregular islands. Figure $1 \mathrm{e}$ shows the $\mathrm{X}$-ray diffraction patterns of $\mathrm{Ni}_{56}$ $\mathrm{Mn}_{25-x} \mathrm{Co}_{x} \mathrm{Ga}_{18.9} \mathrm{Gd}_{0.1}$ alloys, and the matrix is indexed as non-modulated tetragonal-structured martensite $(T)$, and the second phase is face-centered cubic $\gamma$-phase.

In order to confirm the thermomechanical training temperature, the martensitic transformation temperatures are measured by DSC, and the results are exhibited in Fig. 2. The $\mathrm{Ni}_{56} \mathrm{Mn}_{25-x} \mathrm{Co}_{x} \mathrm{Ga}_{18.9} \mathrm{Gd}_{0.1}(x=1,2,4$ and 8$)$ alloys display typical one-step thermoelastic martensitic transformation. The inverse martensitic transformation finishing temperatures $\left(A_{f}\right)$ are $482,510,514$ and $452{ }^{\circ} \mathrm{C}$, respectively. When the $\mathrm{Ni}-\mathrm{Mn}-\mathrm{Ga}$ alloys are deformed, the $A_{f}$ temperature will be increased for dozens of degrees [19]. This phenomenon is attributed to the fact that plastic deformation relaxes the elastic strain energy stored during thermoelastic martensitic transformation, leading to a decrease in the driving force of the martensitic reverse transformation. Therefore, the training temperature of $600{ }^{\circ} \mathrm{C}$ is selected in order to complete inverse martensitic transformation.

The compressive test results prove that the mechanical properties of $\mathrm{Ni}_{56} \mathrm{Mn}_{25-x} \mathrm{Co}_{x} \mathrm{Ga}_{18.9} \mathrm{Gd}_{0.1}$ alloys are significantly enhanced by $\gamma$-phase formation. The compressive fracture strains of dual-phase $\mathrm{Ni}_{56} \mathrm{Mn}_{25-x} \mathrm{Co}_{x} \mathrm{Ga}_{18.9} \mathrm{Gd}_{0.1}$ $(x=2,4$ and 8) alloys can reach 20, 52 and $75 \%$, respectively. It is worth noting that mono-phase $\mathrm{Ni}_{56-}$ $\mathrm{Mn}_{24} \mathrm{Co}_{1} \mathrm{Ga}_{18.9} \mathrm{Gd}_{0.1}$ alloy exhibits poor TWSME less than $0.5 \%$, and an appropriate amount of ductile $\gamma$-phase improves TWSME. Figure 3 shows the strain recovery characteristic curves of $\mathrm{Ni}_{56} \mathrm{Mn}_{25-x} \mathrm{Co}_{x} \mathrm{Ga}_{18.9} \mathrm{Gd}_{0.1}(x=2$, 4 and 8) alloys under the pre-strains of 6 and $8 \%$. The blue arrows represent recovery strain (SME) after being heated to $600{ }^{\circ} \mathrm{C}$ for $1 \mathrm{~min}$, and the purple arrows represent 

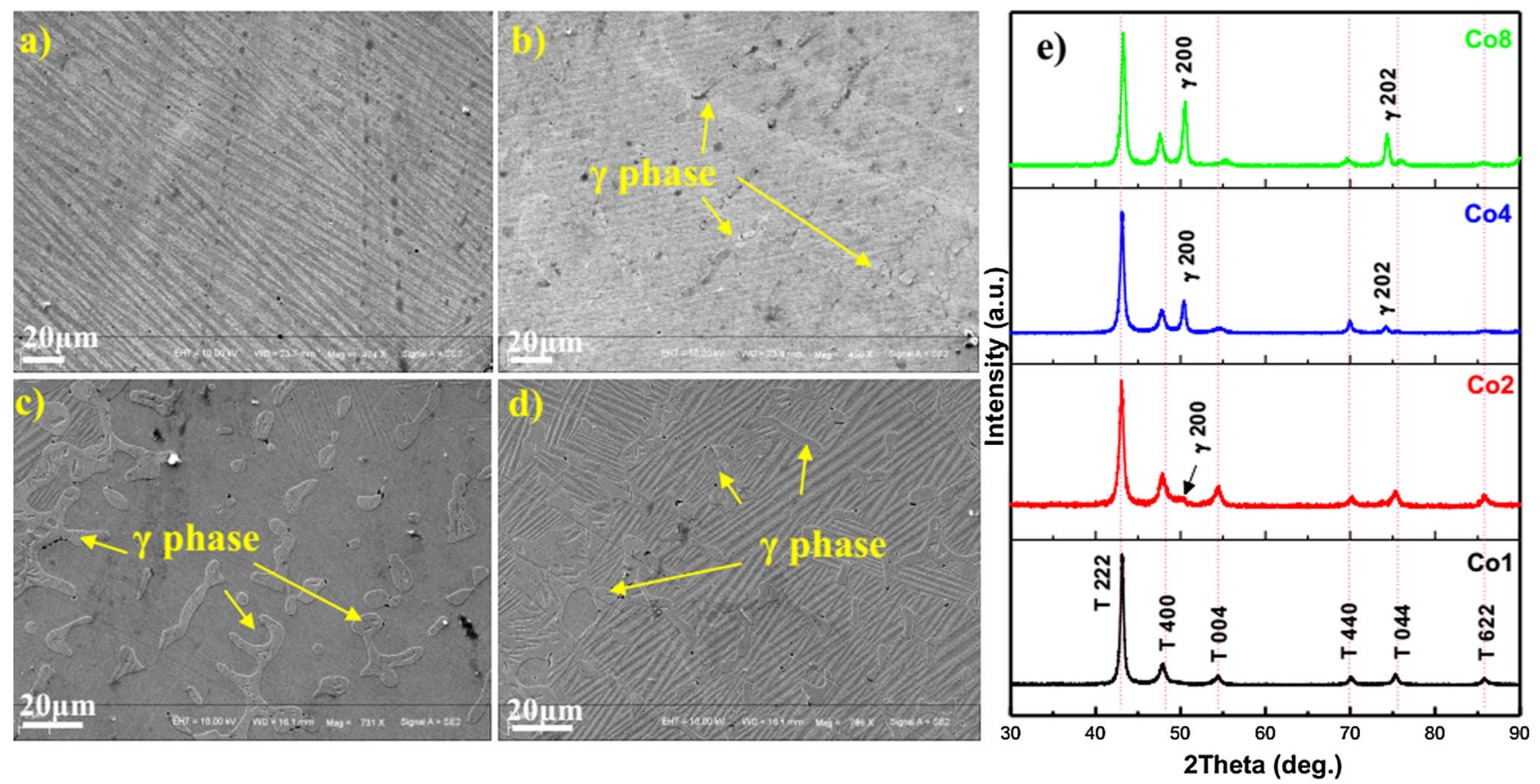

Fig. 1 Secondary electronic images $(\mathbf{a} x=1 ; \mathbf{b} x=2$; $\mathbf{c} x=4$; $\mathbf{d} x=8)$ and e XRD patterns of $\mathrm{Ni}_{56} \mathrm{Mn}_{25-x} \mathrm{Co}_{x} \mathrm{Ga}_{18.9} \mathrm{Gd}_{0.1}$ alloys
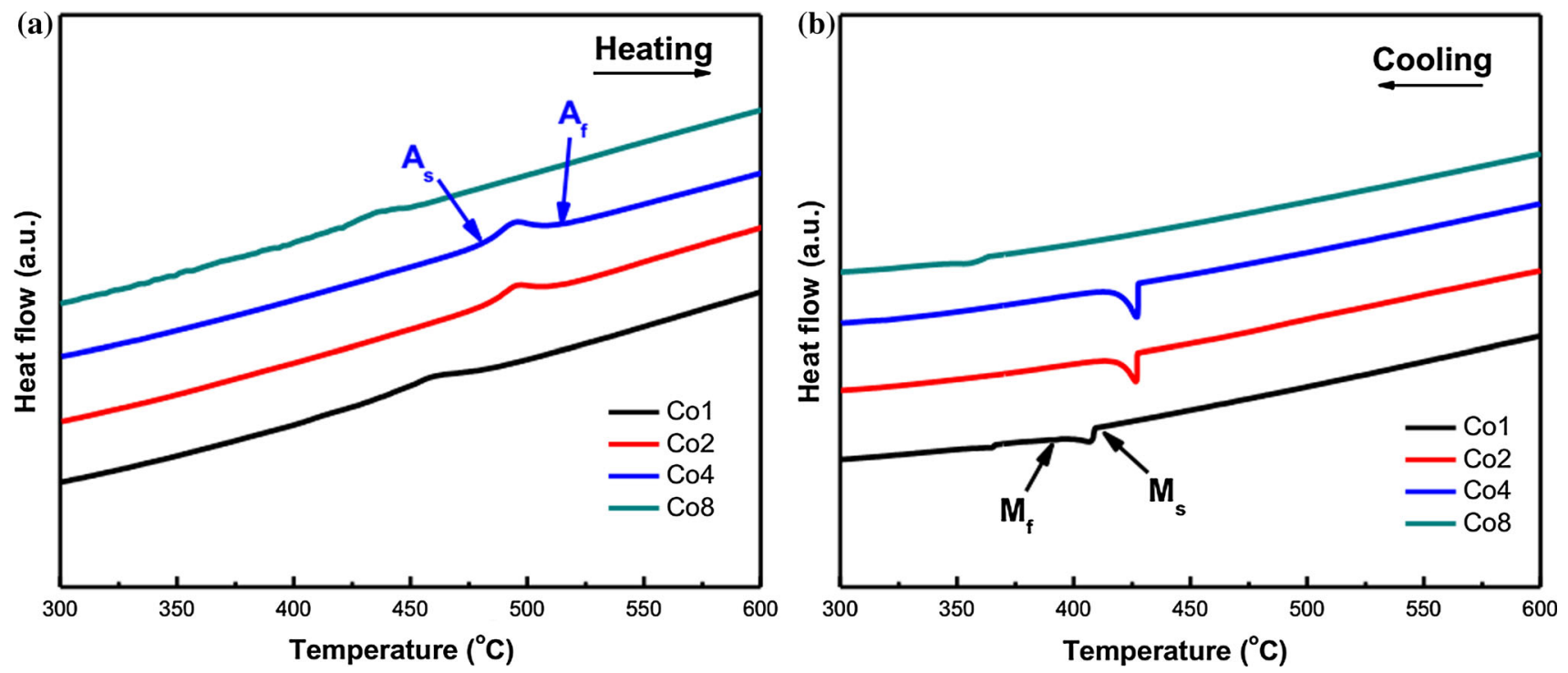

Fig. 2 DSC curves of $\mathrm{Ni}_{56} \mathrm{Mn}_{25-x} \mathrm{Co}_{x} \mathrm{Ga}_{18.9} \mathrm{Gd}_{0.1}$ alloys

TWSME. It can be seen that the SME decreases with the amount of $\gamma$-phase increasing. After the shape recovery is completed, the compressive samples were shortened again with a reduction in temperature, exhibiting the characteristic of TWSME. Although the larger SME is obtained under the pre-strain of $8 \%$, the larger TWSME is measured under the pre-strain of $6 \%$. With the Co content increasing, the TWSME increases and reaches a maximum value of $1.4 \%$ for $x=4$, and then decreases.
Ten thermomechanical training cycles are carried out on $\mathrm{Ni}_{56} \mathrm{Mn}_{25-x} \mathrm{Co}_{x} \mathrm{Ga}_{18.9} \mathrm{Gd}_{0.1}(x=2,4$ and 8) alloys. Figure 4 shows the effect of thermal cycle number on the TWSME. During the first thermal cycle, the TWSMEs of the as-trained alloys are 1.9, 2.0 and $1.3 \%$, respectively. It can be concluded that thermomechanical training enhances the TWSME. The TWSME of the as-trained alloy decreases rapidly in first several cycles and then slowly reaches a stable value as the number of cycle increases further. The degradation of the TWSME can be explained 

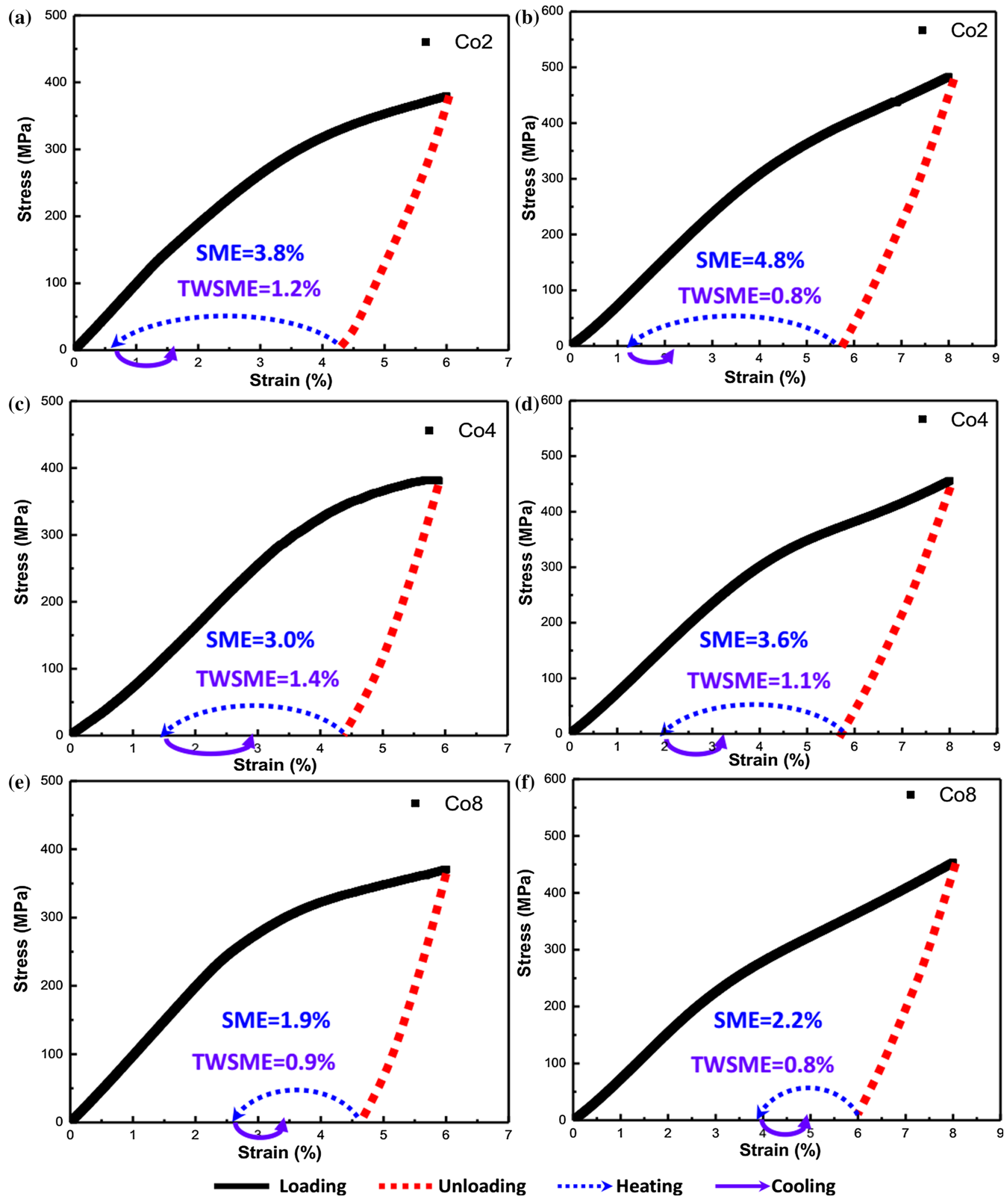

Fig. 3 Strain recovery characteristic curves of $\mathrm{Ni}_{56} \mathrm{Mn}_{25-x} \mathrm{Co}_{x} \mathrm{Ga}_{18.9} \mathrm{Gd}_{0.1}$ alloys under different pre-strain. The blue arrows represent recovery strain after being heated to $600{ }^{\circ} \mathrm{C}$ for $1 \mathrm{~min}$, and the purple arrows represent TWSME 


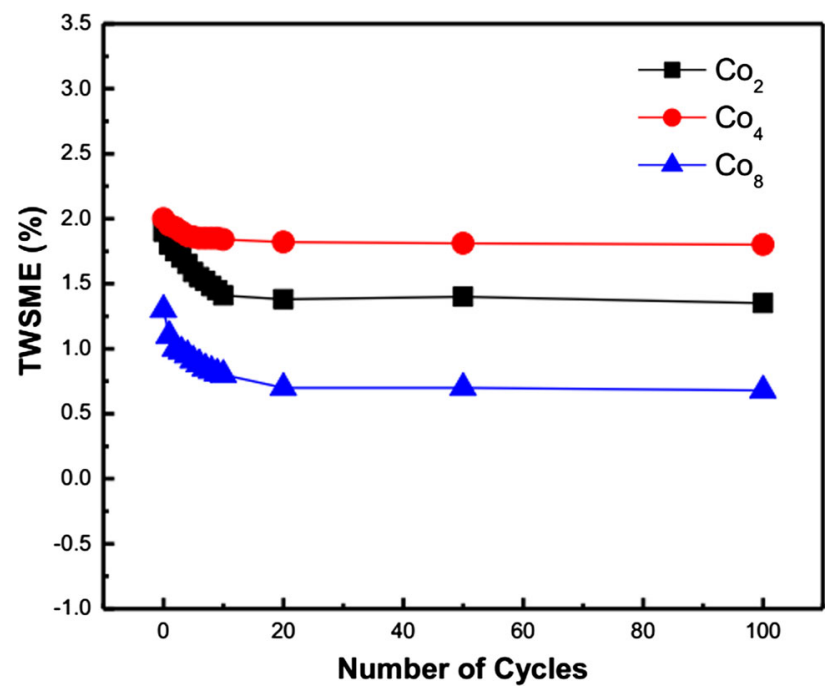

Fig. 4 Effects of thermal cycle number on TWSME in $\mathrm{Ni}_{56} \mathrm{Mn}_{25-x-}$ $\mathrm{Co}_{x} \mathrm{Ga}_{18.9} \mathrm{Gd}_{0.1}$ alloys. The cycle temperature ranges from 25 to $600{ }^{\circ} \mathrm{C}$

by a continual change in the dislocation configuration during thermal cycling, thereby continuously increasing the amount of unfavorably oriented martensite [21].
It is worth noting that the TWSME of the as-trained $\mathrm{Ni}_{56} \mathrm{Mn}_{21} \mathrm{Co}_{4} \mathrm{Ga}_{18.9} \mathrm{Gd}_{0.1}$ alloy reaches a stable value of $1.8 \%$ after only five thermal cycles. Although its TWSME is less than that of $\mathrm{Ni}_{54} \mathrm{Mn}_{25} \mathrm{Ga}_{20.7} \mathrm{Gd}_{0.3}$ alloy with hardbrittle second phase [19], the degradation (0.2\%) and cycle number for stable TWSME are far less than that of $\mathrm{Ni}_{54}$ $\mathrm{Mn}_{25} \mathrm{Ga}_{20.7} \mathrm{Gd}_{0.3}$ alloy, indicating that the thermal stability of TWSME for $\mathrm{Ni}_{56} \mathrm{Mn}_{21} \mathrm{Co}_{4} \mathrm{Ga}_{18.9} \mathrm{Gd}_{0.1}$ alloy is better.

The improvement of TWSME by $\gamma$-phase and the good thermal stability of as-trained dual-phase alloys can be explained as Fig. 5. Thermal martensitic variants display typical self-accommodating morphology, and these variants are replaced by preferred orientation martensitic variants after training, meanwhile, the plastic deformation is occurred in the soft particle of $\gamma$-phase, causing the formation of extra stress field (gray area). In the training process, certain amounts of useful dislocations are introduced. The internal stress field (yellow area) is formed by these dislocations, superposing the extra stress field around $\gamma$-phase to enhance the TWSME of $\mathrm{Ni}_{56} \mathrm{Mn}_{21} \mathrm{Co}_{4} \mathrm{Ga}_{18.9}$ $\mathrm{Gd}_{0.1}$ alloy. Because the extra stress field introduced by deformed $\gamma$-phase is stability, the decay of TWSME is rarely. With the further increase of Co content, the excessive amounts of $\gamma$-phase damages SME and TWSME.
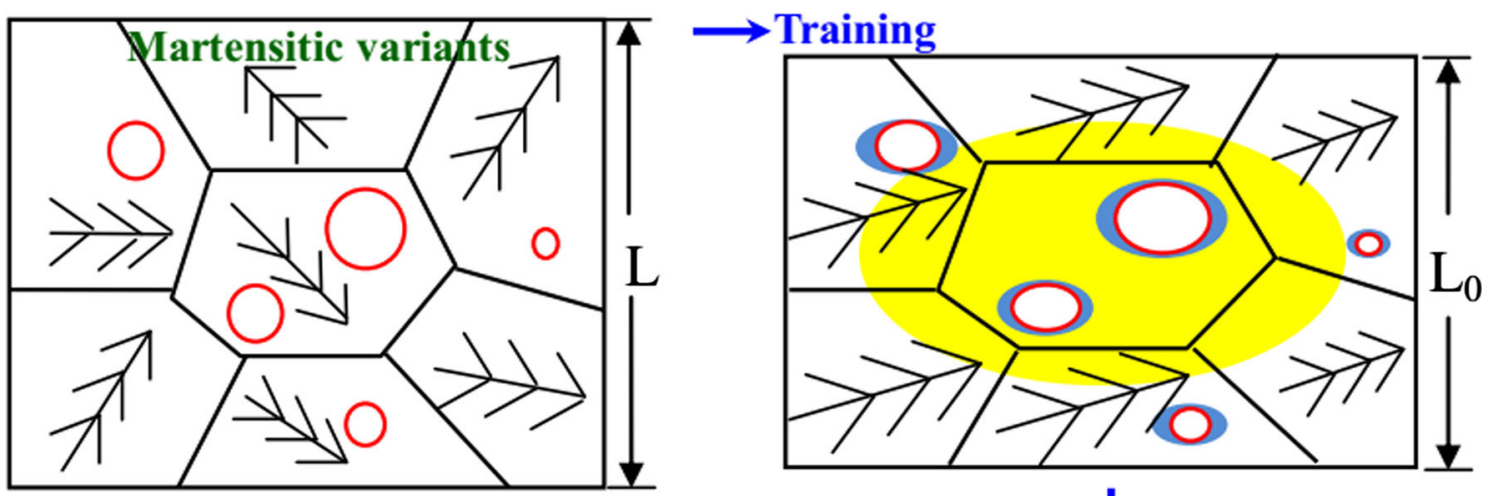

Heating

$\longrightarrow$ Heating
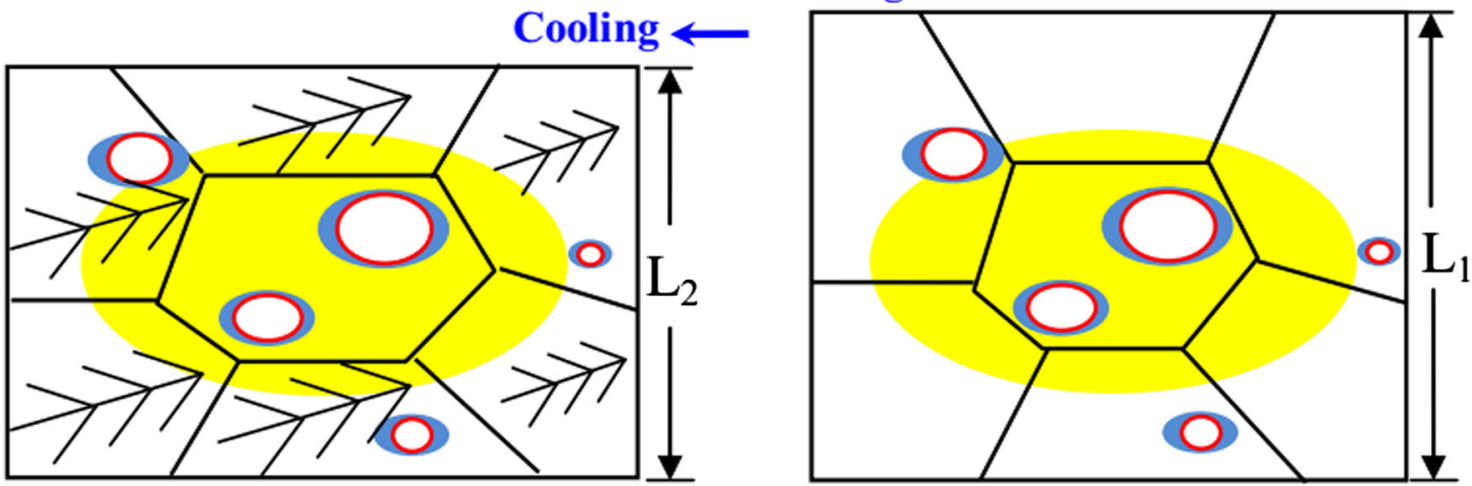

Fig. 5 Schematic diagram showing the effect of $\gamma$-phase on TWSME (arrow denotes martensitic variants, yellow area denotes internal stress field and gray area denotes stress field surrounding the soft $\gamma$-phase) 


\section{Conclusion}

The soft $\gamma$-phase particles can improve the value and stability of TWSME due to its stable deformation stress field. The TWSME of $\mathrm{Ni}_{56} \mathrm{Mn}_{21} \mathrm{Co}_{4} \mathrm{Ga}_{18.9} \mathrm{Gd}_{0.1}$ alloy is enhanced from 1.4 to $2.0 \%$ through thermomechanical training, and this TWSME remains at $1.8 \%$ after 100 thermal cycles.

Acknowledgements This work was supported by the National Natural Science Foundation of China (No. 51601126), the Student's Platform for Innovation and Entrepreneurship Training Program (No. 201710060118) and China Postdoctoral Science Foundation (No. 2016M601271).

\section{References}

[1] Z. Balak, S.M. Abbasi, Mater. Design 32, 3992 (2011)

[2] Y.N. Liu, Y. Liu, J. Van Humbeeck, Acta Mater. 47, 199 (1998)

[3] Y.Q. Ma, C.B. Jiang, Y. Li, H.B. Xu, C.P. Wang, X.J. Liu, Acta Mater. 55, 1533 (2007)

[4] V.A. Chernenko, E. Cesari, V.V. Kokorin, I.N. Vitenko, Scr. Metall. Mater. 33, 123 (1995)

[5] X. Zhang, J.H. Sui, Z.Y. Yang, X.H. Zheng, W. Cai, Mater. Lett. 123, 250-253 (2014)

[6] X. Zhang, Q.S. Liu, X.S. Zeng, J.H. Sui, W. Cai, H.B. Wang, Y. Feng, Intermetallics 68, 113 (2016)
[7] Y. Xin, Y. Li, L. Chai, H.B. Xu, Scr. Mater. 57, 599 (2007)

[8] S.Y. Yang, Y.Q. Ma, H.F. Jiang, X.J. Liu, Intermetallics 19, 225 (2011)

[9] X. Zhang, J.H. Sui, X.H. Zheng, Z.Y. Yang, W. Cai, Mater. Sci. Eng. A A597, 178 (2014)

[10] V.V. Kokorin, V.A. Chernenko, Phys. Met. Metall. 68, 111 (1989)

[11] M. Ohtsuka, M. Matsumoto, K. Itadaki, J. Intel. Mat. Syst. Str. 17, 1069 (2006)

[12] W.H. Wang, G.H. Wu, J.L. Chen, C.H. Yu, S.X. Gao, W.S. Zhan, Z. Wang, Z.Y. Gao, Y.F. Zheng, L.C. Zhao, Appl. Phys. Lett. 77, 3245 (2000)

[13] J.D. Callaway, R.F. Hamilton, H. Sehitoglu, N. Miller, H.J. Maier, Y. Chumlyakov, Smart Mater. Struct. 16, 108 (2007)

[14] V.A. Chernenko, E. Villa, S. Besseghini, J.M. Barandiaran, Phys. Proced. 10, 94 (2010)

[15] H. Scherngell, A.C. Kneissl, Acta Mater. 50, 327 (2002)

[16] X.M. Zhang, J.M. Guilemany, J. Fernandez, M. Liu, L. Liu, Intermetallics 8, 703 (2000)

[17] J.M. Wang, H.Y. Bai, C.B. Jiang, Y. Li, H.B. Xu, Mater. Sci. Eng. A 527, 1975 (2010)

[18] Y.Q. Ma, S.L. Lai, S.Y. Yang, Y. Luo, C.P. Wang, X.J. Liu, Trans. Nonferr. Met. Soc. China 21, 96 (2011)

[19] J.H. Sui, X. Zhang, X.H. Zheng, Z.Y. Yang, W. Cai, X.H. Tian, Scr. Mater. 68, 679 (2013)

[20] S. Datta, A. Bhunya, M.K. Banerjee, Mater. Sci. Eng. A A300, 291 (2001)

[21] H. Scherngell, A.C. Kneissl, Scr. Mater. 39, 205 (1998) 